\title{
KEANEKARAGAMAN JAMUR MAKROSKOPIS DI KAWASAN AIR TERJUN CURUG EMBUN KOTA LUBUKLINGGAU
}

\author{
Erni Afrita ${ }^{1}$, Ria Dwi Jayati2*, Reny Dwi Riastuti ${ }^{3}$ \\ 1,2,33STKIP PGRI Lubuklinggau, Jl. Mayor Toha Kel Air Kuti, Kota Lubuklinggau 31626, \\ Indonesia \\ *Corresponding author, e-mail: ria2jayati@gmail.com
}

\begin{abstract}
This study aims to determine the types, diversity index, species evenness index, dominance index, and relative density of macroscopic fungi in the Waterfall area of Curug Embun, Marga Bakti Village, North Lubuklinggau District I. This research is quantitative descriptive. Data collection techniques in this study using the roaming method with sampling using purposive sampling technique. The results of the analysis of the macroscopic fungal diversity index in the Curug Embun Waterfall area were 1.3530, the species evenness index was 0.4516 , the dominance index was 0.4776 and the highest relative density was $68.027 \%$. There are 3 edible species and 17 non-edible mushrooms. 17 species of macroscopic mushrooms in the Waterfall area of Curug Embun were found. The diversity index, dominance, and Simpson index are in the medium category. Schizophyllum commune is the most commonly found species.
\end{abstract}

Keywords: Diversity, Curug Embun, Macroscopic Fungi

\section{PENDAHULUAN}

Jamur makroskopis adalah jamur yang memiliki ukuran relatif besar (makroskopik), dapat dilihat dengan kasat mata, dapat dipegang, atau dipetik, dan bentuknya beragam misalnya berbentuk seperti payung, kipas dan lainnya (Nasution et al, 2018). Pada umumnya, jamur makroskopis mempunyai warna tubuh yang bermacam-macam yaitu berwarna merah muda, coklat, kuning, putih, putih kekuningan, orange, dan hitam. Bentuk tubuh buah jamur makroskopis yaitu seperti bentuk kipas, ginjal, setengah lingkaran, terompet, dan payung (Rahma et al, 2018). Jamur makroskopis biasanya dapat tumbuh pada media atau tempat yang memiliki humus tinggi, seperti tanah berhumus, pohon yang telah lapuk dan serasah dedaunan (Purwanto et al, 2017).

Jamur makroskopis memiliki beberapa manfaat bagi manusia maupun lingkungannya. Jamur dapat dimanfaatkan oleh manusia sebagai bahan makanan dan obat-obatan, namun ada juga yang bersifat racun (Rahmawati et al, 2018; Riastuti et al., 2018). Jamur yang dapat dikonsumsi mempunyai kandungan garam mineral yang lebih tinggi (Edahwati et al, 2021). Jamur berperan dalam menguraikan bahan organik yang kompleks menjadi sederhana sehingga mudah diserap dan dimanfaatkan oleh organisme lainnya (Solle et al, 2017). Jamur juga membantu menyuburkan tanah melalui penyediaan nutrisi bagi tumbuhan, sehingga hutan tumbuh dengan subur (Nasution et al, 2013). Jamur dapat dijumpai pada kondisi lingkungan yang lembab (Rahma et al, 2018). Salah satu kawasan yang cocok untuk pertumbuhan jamur yaitu di Curug Embun. 
Curug Embun berada di antara kebun masyarakat di Kelurahan Marga Bakti Kecamatan Lubuklinggau Utara I. Curug Embun dimanfaatkan sebagai sumber air minum warga setempat dan untuk mengairi areal pertanian masyarakat. Curug Embun juga menjadi salah satu objek wisata bagi masyarakat setempat di Kelurahan Marga Bakti dan sekitarnya. Adanya aktifitas pengunjung yang kurang memperhatikan akan keberadaan jamur di kawasan Curug Embun, dapat mempengaruhi pertumbuhan jamur. Dikarenakan jamur memerlukan tempat tumbuh yang nyaman, teduh, sejuk, dan lembab (Nurhakim, 2018).

Penelitian ini bertujuan untuk mengetahui jenis, indeks keanekaragaman, indeks kemerataan jenis, indeks dominansi/simpson dan kerapatan relatif jenis jamur makroskopis di kawasan Air Terjun Curug Embun Kelurahan Marga Bakti Kecamatan Lubuklinggau Utara I, Kota Lubuklinggau.

\section{METODE}

Penelitan ini dilakukan pada bulan Mei-Juni 2021 di Kawasan Air Terjun Curug Embun Kelurahan Marga Bakti Kecamatan Lubuklinggau Utara I. Jenis penelitian ini yaitu penelitian kuantitatif yang penggunaan data berupa angka sebagai alat untuk menemukan keterangan mengenai penelitian ini. Penelitian ini menggunakan metode jelajah dengan pengambilan sampel menggunakan teknik purposive sampling, yaitu teknik penentuan sampel dengan pertimbangan tertentu atau seleksi khusus (Syamsuni \& Rantisari, 2021). Dalam penelitian ini peneliti sengaja memilih lokasi di Kawasan Air Terjun Curug Embun Kelurahan Marga Bakti Kecamatan Lubuklinggau Utara I dengan pertimbangan di daerah tersebut banyak ditemukannya jamur.

Prosedur penelitian yang dilakukan peneliti dalam mengumpulkan data yaitu melalui: 1) Persiapan alat dan bahan, 2) Survey Awal Penelitian, 3) Penentuan Lokasi Pengambilan Sampel, 4) Mengukur Faktor Abiotik, 5) Pengambilan Sampel, 6) Analisis Data, data yang di kumpulkan kemudian dianalis secara kuantitatif yaitu dengan menghitung indeks keanekaragaman Shannon-Wienner, indeks kemerataan jenis/keseragaman, indeks dominansi/simpson, dan kerapatan relatif.

\section{HASIL DAN PEMBAHASAN}

\section{Keanekaragaman Jamur Makroskopis di Kawasan Air Terjun Curug Embun}

Hasil penelitian tentang jamur makroskopis yang dilakukan di kawasan Air Terjun Curug Embun Kelurahan Marga Bakti Kecamatan Lubuklinggau Utara I, ditemukan yaitu sebanyak 6 ordo, 12 famili, 17 genus dari 20 spesies.

Tabel 1. Indeks Keanekaragaman, Kemerataan Jenis, dan Dominansi Jamur di Kawasan Air Terjun Curug Embun

\begin{tabular}{ccc}
\hline Indeks & Nilai & Kriteria \\
\hline Keanekaragaman (H') & 1,3530 & Sedang \\
Kemerataan Jenis/Keseragaman (E) & 0,4516 & Sedang \\
Dominansi/Simpson (C) & 0,4776 & Sedang \\
\hline
\end{tabular}

Dari hasil analisis indeks keanekaragaman jamur makroskopis secara keseluruhan di kawasan air terjun Curug Embun Kelurahan Marga Bakti Kecamatan Lubuklinggau Utara I apabila dicocokkan dengan pernyataan Shannon Wienner, maka keanekaragaman jamur makroskopis yang ada di kawasan air terjun Curug Embun dapat dikategorikan keanekaragaman sedang yaitu dengan angka 1,3530. 


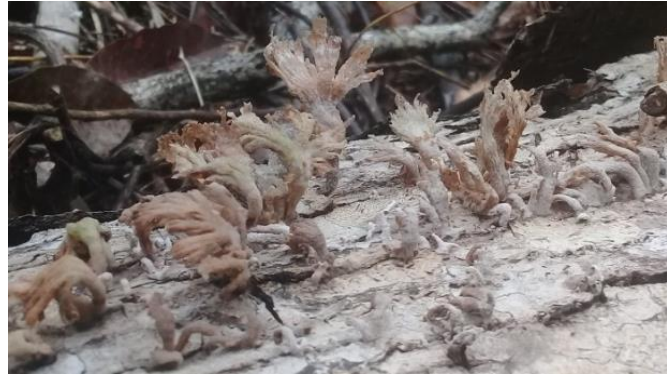

Gambar 1. Schizophyllum commune

(Sumber: Dokumentasi Pribadi, 2021)

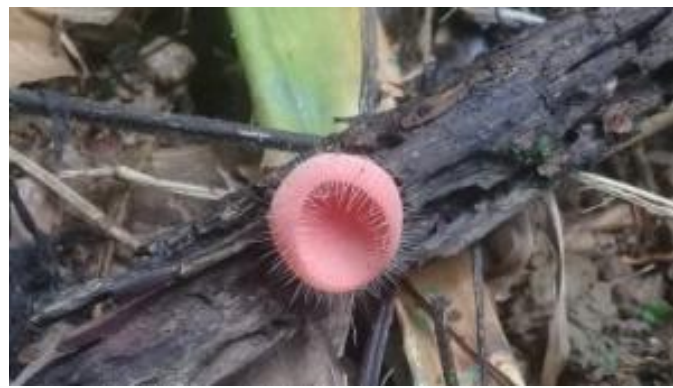

Gambar 3. Cookeina tricholoma

(Sumber: Dokumentasi Pribadi, 2021)

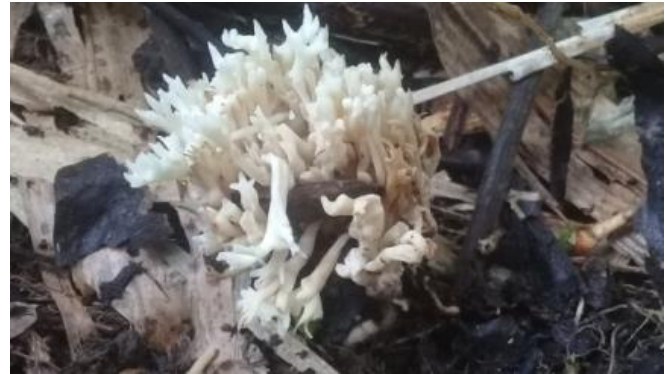

Gambar 2. Clavulina cristata

(Sumber: Dokumentasi Pribadi, 2021)

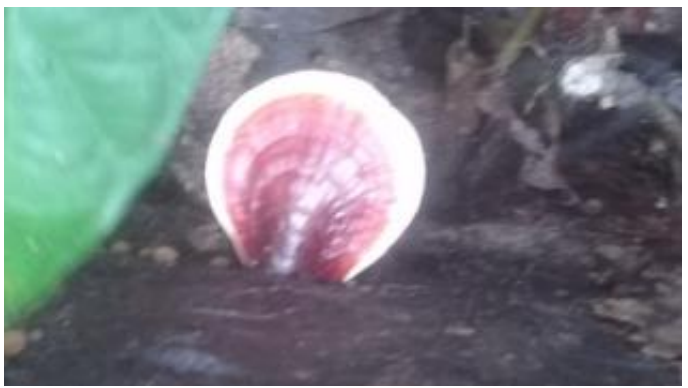

Gambar 4. Ganoderma lucidum

(Sumber: Dokumentasi Pribadi, 2021)

Spesies yang paling banyak dijumpai atau melimpah indeks keanekaragamanya adalah Schizophyllum commune yaitu 0,2621. Jamur Schizophyllum commune ditemukan melimpah dikarenakan hidupnya berkelompok dan ditemukan di kayu yang telah lapuk. Sedangkan di kawasan banyak dijumpai pohon yang tumbang sehingga menjadi faktor pertumbuhan jamur Schizophyllum commune. Sesuai dengan pernyataan Desjardin et al, (2014) bahwa jamur Schizophyllum commune tersebar hingga berkelompok dan menempel pada batang kayu keras yang mati.

Sedangkan spesies yang paling rendah adalah Clavulina cristata, Cookeina tricholoma, dan Ganoderma lucidum yaitu 0,0059. Indeks keanekaragaman suatu jenis dipengaruhi oleh kehadiran jumlah individu pada suatu tempat. Faktor lingkungan yang di ukur pada penelitian ini yaitu suhu udara, kelembaban udara dan $\mathrm{pH}$ tanah. Jumlah individu juga dipengaruhi oleh faktor lingkungan yang dapat mendukung pertumbuhan jamur makroskopis yang meliputi $\mathrm{pH}$, kelembaban, dan suhu (Wati et al, 2019).

Berdasarkan hasil penelitian yang telah dilakukan dapat disimpulkan bahwa tinggi rendahnya keanekaragaman jenis jamur pada suatu lokasi tertentu dipengaruhi oleh faktor abiotik yang mempengaruhi penyebaran dan pertumbuhan jamur (Priskila et al, 2018).

Dari hasil analisis jenis jamur makroskopis di kawasan air terjun Curug Embun memiliki nilai indeks kemerataan jenis sebesar 0,4516 apabila dicocokkan dengan pernyataan Shannon Wienner, maka kemerataan jenis jamur makroskopis yang ada di kawasan Air Terjun Curug Embun dapat dikategorikan kemerataan jenis sedang. Kemerataan jenis yang tinggi apabila semua spesies mempunyai jumlah individu sehingga terjadi keanekaragaman spesies atau diversitas spesies (Solle et al, 2017). 
Jenis-jenis jamur makroskopis yang ditemukan di kawasan penelitian tidak selalu ditemukan pada setiap jalur pengamatan. Hal tersebut berkaitan dengan kondisi iklim di kawasan Air Terjun Curug Embun pada saat pada saat penelitian di musim kemarau. Suhu udara rata-rata berkisar $30,5^{\circ} \mathrm{C}-33,8^{\circ} \mathrm{C}$, dan kelembaban berada sekitar 71\%-89\%. Pada dasarnya jamur akan tumbuh baik dalam kondisi kelembaban yang tinggi. Hal ini sesuai dengan pernyataan (Anggraini et al, 2015) bahwa suhu optimum untuk pertumbuhan jamur yaitu terletak antara $22^{\circ} \mathrm{C}-35^{\circ} \mathrm{C}$ dan kelembaban udara berkisar 70\%-90\%.

Indeks dominansi jamur makroskopis di kawasan air terjun Curug Embun Kelurahan Marga Bakti Kecamatan Lubuklinggau Utara I adalah 0,4776 yang memiliki kriteria indeks dominansi sedang. Spesies yang mendominasi di kawasan air terjun Curug Embun yaitu Schizophyllum commune yang memiliki nilai indeks dominansi 0,4628 dan tergolong ke dalam famili Scizophyllaceae. Schizophyllum commune tergolong dominansi tinggi dikarenakan jamur tersebut merupakan jenis jamur yang paling sering dijumpai di kawasan Curug Embun. Semakin tinggi nilai indeks dominansi, menunjukkan adanya spesies tertentu yang mendominansi, semakin kecil nilai indeks dominansi maka tidak ada spesies yang mendominansi (Annissa et al, 2017).

Tabel 2. Kerapatan Relatif Jamur di Kawasan Air Terjun Curug Embun

\begin{tabular}{rlcc}
\hline No. & \multicolumn{1}{c}{ Nama Spesies } & $\begin{array}{c}\text { Jumlah } \\
\text { Individu }\end{array}$ & Kerapatan Relatif (KR) \\
\hline 1 & Schizophyllum commune & 817 & 68,0270 \\
2 & Dacryopinax spathularia & 24 & 1,9983 \\
3 & Panus neostrigosus & 7 & 0,5828 \\
4 & Pycnoporus sanguineus & 11 & 0,9159 \\
5 & Microporus xanthopus & 5 & 0,4163 \\
6 & Clavulina cristata & 1 & 0,0833 \\
7 & Marasmius candidus & 87 & 7,2440 \\
8 & Clavulinopsis corallinorosacea & 15 & 1,2490 \\
9 & Cookeina sulcipes & 88 & 7,3272 \\
10 & Marasmius haematocephalus & 3 & 0,2498 \\
11 & Thelephora terrestris & 4 & 0,3331 \\
12 & Hirchioporus abietinus & 5 & 0,4163 \\
13 & Cookeina tricholoma & 1 & 0,0833 \\
14 & Cyathus striatus & 59 & 4,9126 \\
15 & Ganoderma lucidum & 1 & 0,0833 \\
16 & Auricularia auricula & 10 & 0,8326 \\
17 & Trametes gibbosa & 9 & 0,7494 \\
18 & Xylaria polymorpha & 12 & 0,9992 \\
19 & Lepiota rubrotincta & 9 & 0,7494 \\
20 & Microporus affinis & 33 & 2,7477 \\
\hline \multicolumn{4}{c}{ Jumlah } \\
\hline
\end{tabular}

Spesies jamur yang memiliki nilai KR tertinggi adalah Schizophyllum commune sebesar 68,027\%. Tingginya kerapatan Schizophyllum commune dikarenakan jamur dari jenis ini hidup secara berkelompok dan dapat tumbuh pada kayu yang telah mati dimana di kawasan Curug Embun cukup banyak ditemukan pohon yang telah tumbang dan mati. Sedangkan jenis yang memiliki nilai KR yang rendah dengan nilai 0,0833\% dengan jumlah spesies jamur ada 3 jenis yaitu, Clavulina cristata, Cookeina tricholoma, dan Ganodema lucidum. 
Kerapatan relatif digunakan untuk mengetahui suatu kerapatan relatif spesies tertentu di suatu daerah. Tingkat kerapatan relatif berhubungan dengan nilai indeks keanekaragaman, semakin tinggi kerapatan maka keanekaragamannya juga tinggi. Tingginya nilai kerapatan suatu jenis jamur dikarenakan jenis jamur tersebut mampu beradaptasi dengan lingkungan sekitar (Triastinurmiatiningsih et al, 2017). Nilai kerapatan yang besar juga disebabkan oleh jumlah individu yang ditemukan dalam jumlah banyak, sehingga diperoleh nilai kerapatan yang besar pula (Wati et al, 2019).

Tabel 3. Suhu Udara, Kelembaban Udara, dan pH Tanah di Kawasan Air Terjun Curug Embun

\begin{tabular}{|c|c|c|c|c|c|c|c|c|c|}
\hline \multirow{2}{*}{$\begin{array}{c}\text { Lokasi } \\
\text { Pengambilan } \\
\text { Sampel } \\
\end{array}$} & \multicolumn{3}{|c|}{$\begin{array}{c}\text { Suhu Udara } \\
\left({ }^{\circ} \mathrm{C}\right)\end{array}$} & \multicolumn{3}{|c|}{ Kelembaban Udara (\%) } & \multicolumn{3}{|c|}{ pH Tanah } \\
\hline & Pagi & Siang & Sore & Pagi & Siang & Sore & Pagi & Siang & Sore \\
\hline $\begin{array}{c}\text { Kawasan } \\
\text { Air Terjun } \\
\text { Curug } \\
\text { Embun }\end{array}$ & $\begin{array}{c}30,5- \\
33,7\end{array}$ & $\begin{array}{c}31- \\
33,8\end{array}$ & $\begin{array}{c}31,2- \\
33,2\end{array}$ & $71-89$ & 71-81 & 74-81 & 7-8 & $7-8$ & $7-8$ \\
\hline
\end{tabular}

Faktor-faktor abiotik yang dapat mempengaruhi pertumbuhan jamur makroskopis di kawasan Air Terjun Curug Embun Kelurahan Marga Bakti Kecamatan Lubuklinggau Utara I memiliki hasil penelitian yang berbeda-beda dikarenakan sesuai dengan kebutuhannya. Suhu udara yang dingin dapat mempengaruhi pertumbuhan jamur makroskopis di kawasan Air Terjun Curug Embun Kelurahan Marga Bakti Kecamatan Lubuklinggau Utara I. Hal ini sesuai dengan pernyataan Purwanto et al (2017), Situmorang et al (2019) yaitu suhu udara optimum untuk pertumbuhan jamur pada kisaran $20^{\circ} \mathrm{C}-35^{\circ} \mathrm{C}$.

Faktor lingkungan sangat menentukan penyebaran atau pertumbuhan jenis jamur yang ada di kawasan air terjun Curug Embun. Jenis-jenis jamur makroskopis yang ditemukan berbeda-beda, hal ini disebabkan oleh perbedaan kondisi lingkungan di kawasan Curug Embun. Sesuai dengan pernyataan Rahmawati et al (2018) bahwa pertumbuhan jamur dipengaruhi oleh lingkungan yang berbeda pada setiap daerah. Namun tipe habitat atau substrat tempat tumbuh jamur juga mempengaruhi pertumbuhan jamur makroskopis (Noverita et al, 2017).

Jamur makroskopis memiliki manfaat yang beragam, tidak hanya dikonsumsi sebagai bahan makanan, jamur juga dapat dijadikan sebagai bahan obat-obatan, maupun souvenir. Namun ada juga jamur yang mempunyai sifat beracun (Annissa et al, 2017). Adapun jamur yang dapat tumbuh alami yaitu jamur kuping (Auricularia auricula) merupakan jamur konsumsi yang cukup disukai oleh masyarakat, karena memiliki cita rasa yang enak (Nasution et al, 2018).

Berdasarkan manfaatnya, jamur makroskopis digolongkan menjadi dua yaitu jamur edible dan jamur non-edible. Jamur edible adalah semua jenis jamur yang dapat dimakan dan atau dapat diolah sebagaimana lazimnya bahan pangan lainnya (Achmad et al, 2011). Jamur yang dapat dikonsumsi biasanya mempunyai kandungan garam mineral yang lebih tinggi dari pada yang dikandung dalam daging sapi atau domba (Siagian et al, 2021). Pada penelitian ini didapatkan jamur makroskopis yang tergolong edible yaitu Schizophyllum commune, Panus neostrigosus, dan Auricularia auricula (Tabel 4). Sedangkan jamur non-edible adalah jamur yang tidak dapat dimakan, atau disebut juga dengan istilah beracun (poisonous). Oleh karena itu, kategori non-edible adalah jamur obat dan jamur beracun (Achmad et al, 2011). 
Tabel 4. Jenis Jamur Makroskopis Edible dan Non Edible

\begin{tabular}{|c|c|c|c|}
\hline \multirow[t]{2}{*}{ No } & \multirow[t]{2}{*}{ Nama Spesies } & \multicolumn{2}{|c|}{ Studi Literatur } \\
\hline & & Edible & Non-Edible \\
\hline 1 & Schizophyllum commune & $\checkmark$ & \\
\hline 2 & Dacryopinax spathularia & & $\checkmark$ \\
\hline 3 & Panus neostrigosus & $\checkmark$ & \\
\hline 4 & Pycnoporus sanguineus & & $\checkmark$ \\
\hline 5 & Microporus xanthopus & & $\checkmark$ \\
\hline 6 & Clavulina cristata & & $\checkmark$ \\
\hline 7 & Marasmius candidus & & $\checkmark$ \\
\hline 8 & Clavulinopsis corallinorosacea & & $\checkmark$ \\
\hline 9 & Cookeina sulcipes & & $\checkmark$ \\
\hline 10 & Marasmius haematocephalus & & $\checkmark$ \\
\hline 11 & Thelephora terrestris & & $\checkmark$ \\
\hline 12 & Hirchioporus abietinus & & $\checkmark$ \\
\hline 13 & Cookeina tricholoma & & $\checkmark$ \\
\hline 14 & Cyanthus striatus & & $\checkmark$ \\
\hline 15 & Ganoderma lucidum & & $\checkmark$ \\
\hline 16 & Auricularia auricula & $\checkmark$ & \\
\hline 17 & Trametes gibbosa & & $\checkmark$ \\
\hline 18 & Xylaria polymorpha & & $\checkmark$ \\
\hline 19 & Lepiota rubrotincta & & $\checkmark$ \\
\hline 20 & Microporus affinis & & $\checkmark$ \\
\hline
\end{tabular}

\section{SIMPULAN}

Berdasarkan hasil penelitian mengenai keanekaragaman jamur makroskopis di kawasan Air Terjun Curug Embun Kelurahan Marga Bakti, Kecamatan Lubuklinggau Utara I ditemukan 17 spesies jamur makrokospis, Indeks Keanekaragaman, Kemerataan Jenis, dan Dominansi Jamur berkategori sedang. Schizophyllum commune merupakan spesies yang paling banyak ditemukan.

\section{REFERENSI}

Achmad., Mugiono., Arlianti, T., \& Azmi, C. (2011). Panduan Lengkap Jamur. Jakarta: Penebar Swadaya.

Anggraini, K., Khotimah, S., \& Turnip, M. (2015). Jenis-Jenis Jamur Makroskopis di Hutan Hujan Mas Desa Kawat Kecamatan Tayan Hilir Kabupaten Sanggau. Jurnal Protobiont, 4(3), 60-64. https://jurnal.untan.ac.id/index.php/jprb/article/download/13305/11996

Annissa, I., Ekamawanti, H. A., \& Wahdina. (2017). Keanekaragaman Jenis Jamur Makrokopis Di Arboretum Sylva Universitas Tanjungpura. Jurnal Hutan Lestari, 5 (4), 969-977. http://dx.doi.org/10.26418/jhl.v9i3.46093

Edahwati, L., Sutiyono, S., Asrori, M. K., \& Anggriawan, R. R. (2021). Analisis Nilai Tambah Pengolahan Jamur Tiram Putih (Pleurotus ostreatus) Menjadi Abon. Jurnal Abdimas Teknik Kimia,2(01), 25-29. http://jatekk.upnjatim.ac.id/index.php/jatekk/article/view/21

Desjardin, D. E., Wood, M. G., \& Stevens, F. A. (2014). California Mushroom The Comprehensive Identification Guide. London: Timber Press. Inc.

Nasution, F., Prasetyaningsih, R. S., \& Ikhwan, M. (2018). Identifikasi Jenis Dan Habitat Jamur Makroskopis Di Hutan Larangan Adat Rumbio Kabupaten Kampar 
Provinsi Riau. Jurnal Kehutanan, 13 (1), 64-76. https://doi.org/10.31849/forestra.v13i1.1556

Noverita, Sinaga, E. \& Setia, T. M. (2017). Inventarisasi Makrofungi Berpotensi Pangan dan Obat di Kawasan Cagar Alam Lembah Anai dan Cagar Alam Batang Palupuh Sumatera. Jurnal Mikologi Indonesia, 1 (1), 15-27. http://doi.org/10.46638/jmi.v1i1.10

Nurhakim, Y. I. (2018). Sukses Budidaya Jamur Tiram. Ilmu Cemerlang Group.

Priskila, Ekamawanti, H. A., \& Herawatiningsih, R. (2018). Keanekaragaman Jenis Jamur Makroskopis Di Kawasan Hutan Sekunder Areal Iuphhk-Hti Pt. Bhatara Alam Lestari Kabupaten Mempawah. Jurnal Hutan Lestari, 6 (3), 569-582. http://dx.doi.org/10.26418/jhl.v6i3.26953

Purwanto, P. B., Zaman, M. N., Yusuf, M., Romli, M., Syafi'i, I. (2017). Inventarisasi Jamur Makroskopis di Cagar Alam Nusakambangan Timur Kabupaten Cilacap Jawa Tengah. Proceeding Biology Education Conference, Yogyakarta. Yogyakarta: Jurusan Biologi UIN Sunan Kalijaga Yogyakarta. https://jurnal.uns.ac.id/prosbi/article/view/18700/14808

Rahma, K. Mahdi, N., \& Hidayat, M. (2018). Karakteristik Jamur Makroskopis Di Perkebunan Kelapa Sawit Kecamatan Meureubo Aceh Barat. Prosiding Seminar Nasional Biotik, Aceh Barat. Aceh Barat: Jurusan Biologi FTK UIN Ar-Raniry Banda Aceh. https://jurnal.arraniry.ac.id/index.php/PBiotik/article/view/4252/2788

Rahmawati, Linda R., \& Tanti N. Y. (2018). Jenis-Jenis Jamur Anggota Kelas Basidiomysetes di Hutan Bayur, Kabupaten Landak, Kalimantan Barat. Jurnal Mikologi Indonesia, 2 (2), 56-66. http://doi.org/10.46638/jmi.v2i2.35.

Riastuti, R., Susanti, I., \& Rahmawati, D. (2018). Eksplorasi Jamur Makroskopis di Perkebunan Kelapa Sawit. BIOEDUSAINS: Jurnal Pendidikan Biologi Dan Sains, 1(2), 126-135. https://doi.org/https://doi.org/10.31539/bioedusains.v1i2.454

Situmorang, E., Jayanthi, S., \& Elfrida. (2019). Keanekaragaman Jenis Jamur Makroskopis Di Taman Hutan Raya Bukit Barisan Kecamatan Dolat Rakyat Kabupaten Karo. Jurnal Jeumpa, 6 (2), 294-300. Doi: https://doi.org/10.33059/jj.v6i2.1780

Solle, H., Klau, F., \& Nuhamara, ST. (2017). Keanekaragaman Jamur di Cagar Alam Gunung Mutis Kabupaten Timor Tengah Utara, Nusa Tenggara Timur. Journal of Biota, 3 (2), 105. https://doi.org/10.24002/biota.v3i2.1886

Siagian, S. M., Febriani, H., \& Hutasuhut, M. A. (2021). Macroscopic Fungi Exploration in Batang Gadis National Park Resort 7 Mandailing Natal District, North Sumatra. Agrinula: Jurnal Agroteknologi dan Perkebunan, 4(2), 139-151. https://doi.org/10.36490/agri.v4i2.169

Syamsuni \& Rantisari, A. M. D. (2021). Statistik Metodologi Penelitian Edisi 2. Jogjakarta: Penerbit KBM Indonesia.

Triastinurmiatiningsih., Haryani, T. S., \& Tampubolon, J. (2017). Keanekaragaman Jenis Jamur di Taman Wisata Alam Situgunung, Cisaat, Sukabumi. Jurnal Ekologia, 17 (1), 7-13. https://doi.org/10.33751/ekol.v17i1.809

Wati, R., Noverita, N., \& Setia, T. M. (2019). Keanekaragaman Jamur Makroskopis Di Beberapa Habitat Kawasan Taman Nasional Baluran: Jurnal Biologi, 12 (2), 171-180. https://doi.org/10.15408/kauniyah.v12i2.10363 